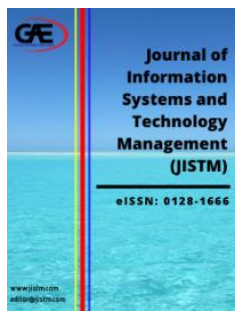

\author{
JOURNAL OF INFORMATION \\ SYSTEM AND TECHNOLOGY \\ MANAGEMENT (JISTM) \\ WWW.jistm.com
}

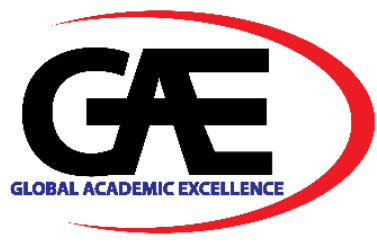

\title{
COMPUTATION OF GRAVITY FIELD FUNCTIONALS WITH A LOCALIZED LEVEL ELLIPSOID
}

\author{
Chivatsi Jonathan Nyoka ${ }^{1}$, Ami Hassan Md Din ${ }^{2 *}$, Muhammad Faiz Pa'suya ${ }^{3}$
}

1 Geospatial Imaging and Information Research Group (GI2RG), Faculty of Built Environment and Surveying, Universiti Teknologi Malaysia, 81310 Skudai, Johor, MALAYSIA.

Email: jnchivatsi@graduate.utm.my

2 Geospatial Imaging and Information Research Group (GI2RG), Geoscience and Digital Earth Centre (INSTeG), Faculty of Built Environment and Surveying, Universiti Teknologi Malaysia, 81310 Skudai, Johor, MALAYSIA.

Email: amihassan@utm.my

3 Environment and Climate Change Research Group, Faculty of Architecture, Planning \& Surveying, Universiti Teknologi MARA, Perlis Branch, Arau Campus, 02600 Arau, Perlis, MALAYSIA

Email: faiz524@uitm.edu.my

* Corresponding Author

\section{Article Info:}

Article history:

Received date: 01.10 .2021

Revised date: 01.11.2021

Accepted date: 20.11.2021

Published date: 01.12.2021

\section{To cite this document:}

Nyoka, C. J., Md Din, A. H., \& Pa'suya, M. F. (2021). Computation Of Gravity Field Functionals With A Localized Level Ellipsoid. Journal of Information System and Technology Management, 6 (24), 226-242.

DOI: $10.35631 / J I S T M .624022$

This work is licensed under $\mathrm{CC}$ BY 4.0 (a)

\section{Abstract:}

The description of the earth's gravity field is usually expressed in terms of spherical harmonic coefficients, derived from global geopotential models. These coefficients may be used to evaluate such quantities as geoid undulations, gravity anomalies, gravity disturbances, deflection of the vertical, etc. To accomplish this, a global reference normal ellipsoid, such as WGS84 and GRS80, is required to provide the computing reference surface. These global ellipsoids, however, may not always provide the best fit of the local geoid and may provide results that are aliased. In this study, a regional or localized geocentric level ellipsoid is used alongside the EGM2008 to compute gravity field functionals in the state of Johor. Residual gravity field quantities are then computed using GNSS-levelled and raw gravity data, and the results are compared with both the WGS84 and the GRS80 equipotential surfaces. It is demonstrated that regional level ellipsoids may be used to compute gravity field functionals with a better fit, provided the zero-degree spherical harmonic is considered. The resulting residual quantities are smaller when compared with those obtained with global ellipsoids. It is expected that when the removecompute-restore method is employed with such residuals, the numerical quadrature of the Stoke's integral may be evaluated on reduced gravity anomalies that are smoother compared to when global equipotential surfaces are used 
Keywords:

Level Ellipsoid, Gravity Field Functionals, Zero-Order Terms

\section{Introduction}

The determination of gravity functionals; geoid undulations, gravity anomalies, gravity disturbances, deflections of the vertical, etc. arises directly from a solution to the disturbing potential of the geodetic boundary value problem. There are two classical formulations of this solution, where gravimetric quantities, e.g. the gravity anomalies, constitute the boundary values (Jekeli, 1999). These two forms are the Stokes formula (Heiskanen and Moritz, 1967; Torge, 2001) and the spherical harmonic series (Macák et al., 2021).

To compute the gravity functionals using spherical harmonic series, coefficients derived from Global geopotential models (GGMs) are required. Many different GGMs have been computed and are currently used in geodetic applications. One of the most accurate and high-frequency global geopotential models, is the EGM2008 model (Pavlis et al., 2012). This model was developed from a combination of GRACE (Gravity Recovery And Climate Experiment) satellite data, a global gravity data grid and topographic data. It is complete to spherical harmonic degree and order 2159 and contains additional coefficients to degree 2190 and order 2159.

As a reference surface for geodetic computations, a global reference normal ellipsoid, such as WGS84 (Meyer, 2002) and GRS80 (Moritz, 1992), is also required. However, these global ellipsoids may not always provide the best fit of the local geoid and may provide results that are aliased. A regional level ellipsoid may be obtained by fitting a bi-axial ellipsoid to the local geoid and making it an equipotential surface with the same mass and angular velocity as the earth.

In this study, a regional geocentric level ellipsoid is used alongside the EGM2008 model to compute gravity field functionals in the state of Johor, Malaysia. The results are compared with gravity functionals obtained with the WGS84 and GRS80 global ellipsoids, as well as with other GGMs. Analysis of the observed gravity field functionals with those obtained by harmonic synthesis, reveals that the regional ellipsoid provides smaller residual values of gravity field functionals. Further, it is revealed that, in the absence of vertical datum bias, ellipsoidal heights derived with regional level ellipsoids may equal orthometric heights to the decimeter level. It is expected that when the remove-compute-restore method is employed with a best-fitting regional ellipsoid, the numerical quadrature of the Stoke's integral may be evaluated on reduced gravity anomalies that are smoother compared to when global equipotential surfaces are used.

\section{Material and Methods}

\section{Data Used}

The research was conducted within the state of Johor, Malaysia. The EGM2008 geopotential model was used to provide the reference for the anomalous gravity field, while a best-fitting regional level ellipsoid was used to act as a reference surface for carrying out computations. 
Volume 6 Issue 24 (December 2021) PP. 226-242 DOI: 10.35631/JISTM.624022

The regional ellipsoid, called Johor2020 for ease of reference in this study, was computed previously, using data covering the entire state of Johor in the south of Malaysia.

\section{Test Data}

Gravity field functionals were computed on test data that contained observed gravity information. The first set contains geodetic positions in WGS84 and orthometric heights of 18 GNSS-Levelling points. These points are situated within the Universiti Teknologi Malaysia (UTM) campus and were derived from Ismail et al. (2018). The second set contains 786 gravity points with their geodetic positions in GRS80 and their gravity acceleration values. Figure 1 shows the positions of all the test data points, while Table 1 and Table 2 show the statistics of the GNSS-levelling and gravity accelerations data used, respectively.

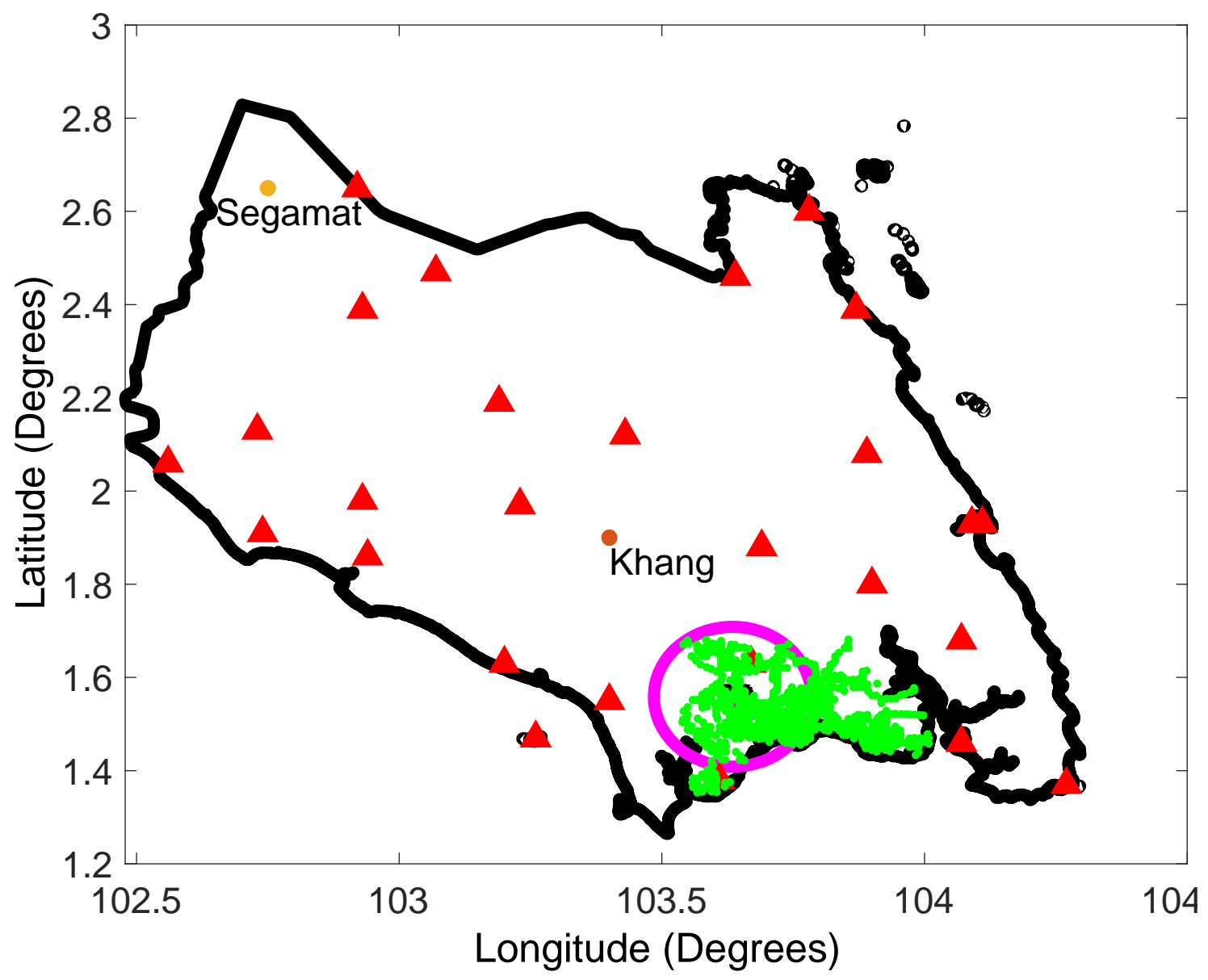

Figure 1: Location of Data in the State of Johor: Red Triangles Indicate the Fiducial Points of the Regional Ellipsoid, Green Dots Are the Gravity Stations, While the Magenta Circle Contains the GNSS-Levelling Test Points 
Table 1: Statistics of GNSS-Levelling Data

\begin{tabular}{ccccc}
\hline & $\begin{array}{c}\text { Longitude } \\
\text { (Degree) }\end{array}$ & $\begin{array}{c}\text { Latitude } \\
\text { (Degree) }\end{array}$ & $\begin{array}{c}\text { Ellipsoidal } \\
\text { Height (Metre) }\end{array}$ & $\begin{array}{c}\text { Orthormetric } \\
\text { Height (Metre) }\end{array}$ \\
\hline Min & 103.627543 & 1.551658 & 18.066200 & 10.149600 \\
Max & 103.644327 & 1.565662 & 53.581400 & 45.684400 \\
Mean & 103.634734 & 1.558556 & 33.011017 & 25.106006 \\
Std & 0.005164 & 0.004217 & 9.467911 & 9.477679 \\
\hline
\end{tabular}

Table 2: Statistics of Gravity Acceleration Data

Longitude Latitude Ellipsoidal Gravity

(Degree) (Degree) Height (Metre) Acceleration

\begin{tabular}{ccccc} 
& & & & (mgal) \\
\hline Min & 103.539238 & 1.353234 & 0.000000 & 970845.939000 \\
Max & 104.007836 & 1.681284 & 102.971350 & 978070.777000 \\
Mean & 103.743520 & 1.527154 & 32.316143 & 977642.558691 \\
Std. & 0.115721 & 0.066228 & 15.436222 & 1673.237516 \\
\hline
\end{tabular}

The parameters of the regional ellipsoid are shown in Table 3, while Table 4 contains the parameters of the global ellipsoids.

Table 3: Physical Constants of Johor2020 Ellipsoid (Exact)

\begin{tabular}{cllc}
\hline Symbol & \multicolumn{1}{c}{ Parameter } & \multicolumn{1}{c}{ Value } & Units \\
\hline$a$ & semi-major axis & 6378145.549089 & $\mathrm{~m}$ \\
$1 / f$ & reciprocal of flattening & 269.792502072 & $\mathrm{~m}^{-1}$ \\
$\omega_{e}$ & angular velocity & $7.292115 \mathrm{e}-05$ & $\mathrm{rad} / \mathrm{s}$ \\
$\mathrm{GM}$ & $\begin{array}{l}\text { geocentric gravitational } \\
\text { constant }\end{array}$ & $3.986005000 \mathrm{e}+14$ & $\mathrm{~m}^{3} / \mathrm{s}^{2}$ \\
$U_{0}$ & $\begin{array}{l}\text { Normal potential on the } \\
\text { ellipsoid }\end{array}$ & 62644167.009035 & $\mathrm{~m}^{2} / \mathrm{s}^{2}$ \\
$\gamma_{m}$ & $\begin{array}{l}\text { Mean gravity on the } \\
\text { ellipsoid }\end{array}$ & 9.788 & $\mathrm{~m} / \mathrm{s}^{2}$ \\
$R_{m}$ & Mean radius of ellipsoid & 6370265.239221 & $\mathrm{~m}$ \\
\hline
\end{tabular}

Table 4: Physical Constants of Global Ellipsoid (Exact)

\begin{tabular}{clllc}
\hline Symbol & \multicolumn{1}{c}{ Parameter } & \multicolumn{1}{c}{ WGS84 } & \multicolumn{1}{c}{ GRS80 } & Units \\
\hline$a$ & semi-major axis & 6378137 & 6378137 & $\mathrm{~m}$ \\
$1 / f$ & reciprocal of & 298.257223563 & 298.257222096042 & $\mathrm{~m}^{-1}$ \\
& flattening & & & \\
$\omega_{e}$ & angular velocity & $7.292115 \mathrm{e}-05$ & $7.292115 \mathrm{e}-05$ & $\mathrm{rad} / \mathrm{s}$ \\
$\mathrm{GM}$ & geocentric & $3.986004418 \mathrm{e}+14$ & $3.986005000 \mathrm{e}+14$ & $\mathrm{~m}^{3} / \mathrm{s}^{2}$ \\
& gravitational & & & \\
& constant & & & $\mathrm{m}^{2} / \mathrm{s}^{2}$ \\
$U_{0}$ & Normal potential & 62636851.7146 & 62636860.850 &
\end{tabular}




\begin{tabular}{llccc}
$\gamma_{m}$ & $\begin{array}{l}\text { Mean gravity on } \\
\text { the ellipsoid }\end{array}$ & 9.7976432222 & 9.797644656 & $\mathrm{mOI:} \mathrm{10.35631/JISTM.62}$ \\
$R_{m}$ & $\begin{array}{l}\text { Mean radius of } \\
\text { ellipsoid }\end{array}$ & 6371008.771 & 6371008.771 & $\mathrm{~m}$ \\
\hline
\end{tabular}

\section{Methods Used}

In this section, a mathematical background on the computation of gravity field functionals using GGMs is summarized.

\section{The Anomalous Potential}

The determination of the gravimetric functionals, e.g. geoid undulations, gravity anomalies, gravity disturbances, gradients and vertical deflections is accomplished from a solution to the disturbing potential. The anomalous (disturbing) gravity potential, $T$ at point, $P_{(r, \vartheta, \lambda)}$ is the difference between the real gravity potential, $W_{P}$, and the gravity potential, $U_{P}$, of the reference level ellipsoid (Barthelmes, 2013):-

$$
T_{(r, \vartheta, \lambda)}=W_{(r, \vartheta, \lambda)}-U_{(r, \vartheta, \lambda)}
$$

where, $(r, \vartheta, \lambda)$ are the spherical coordinates: $r$ being the radius vector, $\vartheta$ the polar angle (colatitude) measured with respect to the rotational axis, and $\lambda$ is the longitude measured in the equatorial plane.

The gravity potential, $W(r, \vartheta, \lambda)$ is given by: -

$$
W(r, \vartheta, \lambda)=V_{g}+\frac{1}{2} \omega^{2} r^{2} \sin ^{2} \vartheta
$$

where $V_{g}$ is the gravitational potential and the second term of equation (2) is the contribution of the centrifugal force caused by the earth's rotation.

The quantity $U$ is the normal gravity potential generated by a perfect fluid being rigidly rotated with respect to celestial reference frame with a constant angular velocity, $\omega$ (Sjöberg and Bagherbandi, 2017):-

$$
U(r, \vartheta)=U_{g}(r, \vartheta)+\frac{1}{2} \omega^{2} r^{2} \sin ^{2} \vartheta
$$

where $U_{g}(r, \vartheta)$ is the normal axisymmetric gravitational potential determined inside the mass distribution.

When using an equipotential ellipsoid of the same mass and same angular velocity as the earth, the effect of the centrifugal forces cancels out in equation (1), and the disturbing potential is reduced to (Barthelmes, 2013):-

$$
T_{(r, \vartheta, \lambda)}=V_{g_{(r, \vartheta, \lambda)}}-U_{g_{(r, \vartheta)}}
$$

The actual and normal gravitational potentials of the earth and equipotential ellipsoid are both harmonic on and exterior to the surface of the earth, and may be expressed as a series of 
spherical harmonic coefficients (Moritz, 1980; Jekeli, 2000; Torge, 2001; Moazezi \& Zomorrodian, 2012):-

$$
\begin{aligned}
V_{g}(r, \vartheta, \lambda)= & \frac{G M_{E}}{r} \mid 1 \\
& \left.\quad+\sum_{n=2}^{\infty}\left(\frac{a}{r}\right)^{n} \sum_{m=0}^{n}\left\{\bar{C}_{n m} \cos (m \lambda)+\bar{S}_{n m} \sin (m \lambda)\right\} \bar{P}_{n m} \cos (\vartheta)\right]
\end{aligned}
$$

where $G M_{E}$ is the product of the Newtonian gravitational constant and mass of the GGM, $a$ is the mean earth radius, $\bar{C}_{n m}$ and $\bar{S}_{n m}$ are the fully normalized coefficients of the geopotential models with degree $n$ and order $m, \bar{P}_{n m}$ is the fully normalized associated Legendre's function, and other variables are as previously defined.

Similarly, the gravitational potential of an equipotential ellipsoid (gravity potential minus the centrifugal potential) may be expressed as a series of spherical harmonics (Moritz, 1980; Jekeli, 2000; Torge, 2001):-

$$
U_{g}(r, \vartheta)=\frac{G M}{r}\left\{1-\sum_{n=1}^{\infty} J_{2 n}\left(\frac{a}{r}\right)^{2 n} P_{2 n} \cos \vartheta\right\}
$$

where $G M$ is the geocentric gravitational constant of the Earth. The term $J_{2 n}$ are the zonal harmonic coefficients which are expressed as:-

$$
\begin{gathered}
J_{2 n}=(-1)^{n+1} \frac{3 e^{2 n}}{(2 n+1)(2 n+3)}\left\{1-n+5 n \frac{J_{2}}{e^{2}}\right\} \\
J_{2}=\frac{e^{2}}{3}\left(1-\frac{2}{15} \frac{m e^{\prime}}{q_{0}}\right) \\
q_{0}=\frac{1}{2}\left(1+3 e^{\prime 2}\right) \tan ^{-1} e^{\prime}-\frac{3}{e^{\prime}}
\end{gathered}
$$

where $J_{2}$ is the dynamic form factor, $e$ and $e^{\prime}$ are the first and second eccentricity, respectively, of the ellipsoid, and $P_{n} \cos \varphi$ is the legendre polynomial of order, $n$

\section{Computation of Geoid Undulation}

Using the theorem of Brun's, the geoidal undulation at any point $\mathrm{P}$, may be obtained from the formulae (Tugi et al., 2016; Trojanowicz et al., 2020;):- 


$$
N(r, \vartheta, \lambda)=\frac{T(r, \vartheta, \lambda)}{\gamma(r, \vartheta)}
$$

where $y(r, \vartheta)$ is the normal gravity on the ellipsoid that may be obtained from Somigliana's formula as a function of the point's latitude $\varphi$ (Moritz, 1992; Torge, 2001):-

$$
\gamma_{e l l}=\frac{a \gamma_{e} \cos ^{2} \varphi+b \gamma_{p} \sin ^{2} \varphi}{\left(a^{2} \cos ^{2} \varphi+b^{2} \sin ^{2} \varphi\right)^{1 / 2}}
$$

Or from the Pizzeti formulae (Moritz, 1992; Torge, 2001):-

$$
\gamma_{e l l}=\frac{\gamma_{e}\left(1+k \sin ^{2} \varphi\right.}{\sqrt{1+e^{2} \sin ^{2} \varphi}}
$$

where $\gamma_{e}$ is the normal gravity at the equator, $\gamma_{p}$ is the normal gravity at the poles, $b$ is the semi-minor axis of the ellipsoid, and

$$
k=\frac{b \gamma_{p}}{a \gamma_{e}}-1
$$

\section{Computation of Gravity Disturbance}

The gravity disturbance is defined as the difference between the actual and normal gravity at the same point, and is equal to the gradient of the disturbing potential (Barthelmes, 2013):-

$$
\begin{gathered}
\delta g(r, \vartheta, \lambda)=g_{p}(r, \vartheta, \lambda)-\gamma_{p}(r, \vartheta) \\
\nabla T(r, \vartheta, \lambda)=|\nabla V(r, \vartheta, \lambda)|-|\nabla U(r, \vartheta)|
\end{gathered}
$$

where $\nabla=\frac{\partial f}{\partial \mathrm{r}} \vec{e}_{r}+\frac{\partial f}{\partial \vartheta} \vec{e}_{\vartheta}+\frac{\partial f}{\partial \lambda} \vec{e}_{\lambda}$ is the nabla operator representing the unit vectors in the direction $r, \vartheta$, and $\lambda$., and $\gamma_{p}(r, \vartheta)$ is the normal gravity on the surface of the Earth which can be calculated by the following formula (Moritz, 1992; Torge, 2001):-

$$
\gamma_{P}=\gamma_{0}\left\{1-2\left(1+f+m-2 f \sin ^{2} \varphi\right) \frac{h}{a}+3\left(\frac{h}{a}\right)^{2}\right\}
$$

where $h$ is the geodetic height of point $P$ and other parameters are as defined earlier. 
The gradient of the actual potential, $V$ may be computed in the foresaid directions from the following equations (Barthelmes, 2013; Tugi et al., 2016; Kosarev et al., 2018):-

$$
\begin{aligned}
& \frac{\partial V_{g}(\vartheta, \lambda, r)}{\partial r}=\frac{G M}{r^{2}} \mid 1 \\
& +\sum_{n=2}^{\infty}\left(\frac{a}{r}\right)^{n}(n \\
& \text { + 1) } \sum_{m=0}^{n}\left\{\bar{C}_{n m} \cos (m \lambda)+\bar{S}_{n m} \sin (m \lambda)\right\} \bar{P}_{n m} \cos (\vartheta) \\
& \frac{\partial V_{g}(\vartheta, \lambda, r)}{\partial \lambda}=\left.\frac{G M}{r}\right|_{1} \\
& +\sum_{n=2}^{\infty}\left(\frac{a}{r}\right)^{n} \sum_{m=0}^{n}\left\{\bar{S}_{n m} \cos (m \lambda)-C_{n m} \sin (m \lambda)\right\} m \bar{P}_{n m} \cos (\vartheta) \\
& \frac{\partial V_{g}(\vartheta, \lambda, r)}{\partial \vartheta}=\left.\frac{G M}{r}\right|_{\infty} 1 \\
& \left.+\sum_{n=2}^{\infty}\left(\frac{a}{r}\right)^{n} \sum_{m=0}^{n}\left\{\bar{C}_{n m} \cos (m \lambda)+\bar{S}_{n m} \sin (m \lambda)\right\} \frac{\partial \bar{P}_{n m} \cos (\vartheta)}{\partial \vartheta}\right]
\end{aligned}
$$

Similar equations may be written for the normal potential (Barthelmes, 2013; Kosarev et al., 2018):-

$$
\begin{gathered}
\frac{\partial U_{g}(\vartheta, r)}{\partial r}=-\frac{G M}{r^{2}}\left[1-\sum_{n=1}^{\infty} J_{2 n}\left(\frac{a}{r}\right)^{2 n}(2 n+1) P_{2 n} \cos \varphi\right\rfloor \\
\frac{\partial U_{g}(\vartheta, r)}{\partial \lambda}=0 \\
\frac{\partial U_{g}(\vartheta, r)}{\partial \vartheta}=\frac{G M}{r}\left\{1-\sum_{n=1}^{\infty} J_{2 n}\left(\frac{a}{r}\right)^{2 n} \frac{\partial P_{2 n} \cos \vartheta}{\partial \vartheta}\right\}
\end{gathered}
$$

For the evaluation of first-order derivatives $\bar{P}_{n m} \cos (\vartheta)$ of the fully normalized Associated Legendre Function, the reader is referred to e.g., (Bosch, 2000; Petrovskaya and Vershkov, 2012)

In spherical approximation, as was used in this study, the gravity disturbance may be obtained in the radial direction (Barthelmes, 2013; Kosarev et al., 2018):-

$$
\delta g=\frac{\partial T}{\partial r}=\frac{\partial V_{g}(\vartheta, \lambda, r)}{\partial r}-\frac{\partial U_{g}(\vartheta, r)}{\partial r}
$$




\section{Computation of Gravity Anomaly}

The gravity anomaly is defined as the difference between the gravity at a given point and the normal gravity on a reference equipotential Surface (Jekeli, 2000; Moazezi \& Zomorrodian, 2012; Moritz, 1980; Torge, 2001):-

$$
\Delta g(r, \vartheta, \lambda)=g_{p}(r, \vartheta, \lambda)-\gamma_{r}(r, \vartheta)
$$

The disturbing potential, $\mathrm{T}$, the Gravity disturbance, and gravity anomaly are related via the fundamental equation of physical geodesy, which expresses the gravity anomaly as a function of the disturbing potential (Moritz, 1980; Jekeli, 2000; Torge, 2001; Moazezi \& Zomorrodian, 2012):-

$$
\Delta g=-\frac{\partial T}{\partial r}-\frac{2}{R} T=\delta g-\frac{2}{R} T
$$

\section{Computation of Deflections of The Vertical}

The deflection of the vertical is the angle between the direction of the gravity vector at a point and the ellipsoidal normal through the same point. It is conventionally composed of two perpendicular components: a north-south meridional component and an east-west prime vertical component.

In spherical approximation and Molodensky definition, the North-South vertical deflection $\xi$ is computed as a function of the latitudinal derivative (Hirt, 2010):-

$$
\xi=\frac{1}{\gamma r} \frac{\partial T}{\partial \vartheta}
$$

Where,

$$
\frac{\partial T}{\partial \vartheta}=\frac{\partial V_{g}(\vartheta, \lambda, r)}{\partial \vartheta}-\frac{\partial U_{g}(\vartheta, r)}{\partial \vartheta}
$$

Similarly, the east-west component, $\eta$ may be expressed as function of the longitudinal derivative (Hirt, 2010):-

$$
\begin{gathered}
\eta=\frac{1}{\gamma r \cos (\vartheta)} \frac{\partial T}{\partial \lambda} \\
\frac{\partial T}{\partial \lambda}=\frac{\partial V_{g}(\vartheta, \lambda, r)}{\partial \lambda}-\frac{\partial U_{g}(\vartheta, r)}{\partial \lambda}
\end{gathered}
$$

Due to lack of test data, the computation of deflections of the vertical will not be pursued further in this study. 


\section{Computation of Zero Degree Term}

In equations (4), (5) and (6), a zero-degree term $(n=0)$ in the spherical harmonic expansion of the disturbing potential, must be included in the computation to cater for the difference in the estimates of the geopotential constant, $G M_{E}$ and the gravity potential, $W_{0}$ on the surface of the geoid used by the GGM and those adopted for the normal ellipsoid, unless the quantities are assumed to be equal. Of course, these assumptions are not valid for the regional ellipsoid used in this study, and therefore zero-degree terms for the different functionals were added to the result to cater for the difference as aforementioned.

In the generalized expansion of the disturbing potential in spherical harmonics, it may be expressed as (Kirby and Featherstone, 1997):-

$$
T=T_{0}+\sum_{n=2}^{\infty} T_{n}
$$

where $T_{n}$ is the spherical harmonic of degree $n$ and $T_{0}$ is the zero degree harmonic. $T_{0}$ may be expressed as (Kirby and Featherstone, 1997):-

$$
T_{0}=\frac{G M_{E}-G M_{0}}{R}+W_{0}-U_{0}
$$

where the parameters $G M_{0}$ and $U_{0}$ correspond to the Somigliana-Pizzeti normal gravity field generated by the normal ellipsoid (Moritz, 1992), $\gamma$ is the normal gravity on the surface of the ellipsoid, $R$ is the mean radius of the earth and other quantities are as previously defined.

The first term of equation (31) is already catered for when computing the disturbing potential using equation (4). The second term, however, must be computed separately. The first degree harmonic in equation (30) may be omitted if the coordinate system is assumed to be geocentric (Heiskanen \& Moritz, 1967; Jekeli, 1999; Kirby \& Featherstone, 1997).

\section{Geoid Height, $N_{0}$}

This term constitutes the component of the zero-degree harmonic to the GGM geoid undulations with respect to the reference normal ellipsoid. It is computed from equation (31) with the general Brun's formula (Heiskanen and Moritz, 1967; Kirby and Featherstone, 1997) :-

$$
N_{0}=\frac{G M_{E}-G M_{0}}{R \gamma}-\frac{W_{0}-U_{0}}{\gamma}
$$

\section{Gravity Disturbance, $\delta g_{0}$}

The zero degree harmonic of the gravity disturbance may be computed from (Heiskanen and Moritz, 1967; Kirby and Featherstone, 1997):-

$$
\delta g_{0}=\operatorname{grad}\left(T_{0}\right)=\frac{G M_{E}-G M_{0}}{R^{2}}
$$


Gravity Anomaly, $\Delta g_{0}$

The zero degree harmonic of gravity anomaly may be expressed from the fundamental equation of physical geodesy (equation (25)) (Heiskanen and Moritz, 1967; Kirby and Featherstone, 1997):-

$$
\begin{gathered}
\Delta g=\delta g-\frac{2}{R} T \\
\Delta g+\Delta g_{0}=\left(\delta g+\delta g_{0}\right)-\frac{2}{R}\left(T+T_{0}\right) \\
\Delta g_{0}=\frac{G M_{E}-G M_{0}}{r^{2}}-\frac{2\left(W_{0}-U_{0}\right)}{r}
\end{gathered}
$$

Where parameters are as previously defined.

\section{Main Results}

\section{Conversion of Test Data}

The GNSS/levelling test data, which was given in WGS84, was first converted to the other ellipsoidal systems using well-known equations for converting between Earth-centred-earthfixed (ECEF) and geodetic coordinates. The statistics of the converted data is shown in Table 5 and Table 6.

Table 5: Statistics of GNSS-Levelling Data In GRS80

\begin{tabular}{lllll}
\hline & $\begin{array}{l}\text { Longitude } \\
\text { (Degree) }\end{array}$ & $\begin{array}{l}\text { Latitude } \\
\text { (Degree) }\end{array}$ & $\begin{array}{l}\text { Ellipsoidal } \\
\text { Height } \\
\text { (Metre) }\end{array}$ & $\begin{array}{l}\text { Orthormetric } \\
\text { Height (Metre) }\end{array}$ \\
\hline Minimum & 103.627543 & 1.551658 & 18.066200 & 10.149600 \\
Maximum & 103.644327 & 1.565662 & 53.581400 & 45.684400 \\
Mean & 103.634734 & 1.558556 & 33.011017 & 25.106006 \\
Std Dev. & 0.005164 & 0.004217 & 9.467911 & 9.477679 \\
\hline
\end{tabular}

Table 6: Statistics of GNSS-Levelling Data In Johor2020

\begin{tabular}{lllll}
\hline & $\begin{array}{l}\text { Longitude } \\
\text { (Degree) }\end{array}$ & $\begin{array}{l}\text { Latitude } \\
\text { (Degree) }\end{array}$ & $\begin{array}{l}\text { Ellipsoidal } \\
\text { Height } \\
\text { (Metre) }\end{array}$ & $\begin{array}{l}\text { Orthormetric } \\
\text { Height (Metre) }\end{array}$ \\
\hline Minimum & 103.627543 & 1.552760 & 11.169856 & 10.149600 \\
Maximum & 103.644327 & 1.566774 & 46.710001 & 45.684400 \\
Mean & 103.634734 & 1.559662 & 26.126317 & 25.106006 \\
Std Dev. & 0.005164 & 0.004220 & 9.472148 & 9.477679 \\
\hline
\end{tabular}


Similarly, the gravity acceleration data was converted from the GRS80 system into the other ellipsoid systems, as shown in Table 7 and Table 8.

Table 7: Statistics of Gravity Accelerations In WGS84

\begin{tabular}{lcccc}
\hline & $\begin{array}{c}\text { Longitude } \\
\text { (Degree) }\end{array}$ & $\begin{array}{l}\text { Latitude } \\
\text { (Degree) }\end{array}$ & $\begin{array}{c}\text { Ellipsoidal } \\
\text { Height } \\
\text { (Metre) }\end{array}$ & $\begin{array}{c}\text { Gravity } \\
\text { Acceleration } \\
\text { (Mgal) }\end{array}$ \\
\hline Minimum & 103.556806 & 1.364710 & 9.975000 & 978039.034000 \\
Maximum & 103.566782 & 1.636153 & 63.572000 & 978056.960000 \\
Mean & 103.561453 & 1.469545 & 27.438395 & 978050.664900 \\
Std. Dev. & 0.004071 & 0.093409 & 23.288736 & 6.316135 \\
\hline
\end{tabular}

Table 8: Statistics of Gravity Accelerations In Johor2020

\begin{tabular}{lllll}
\hline & $\begin{array}{l}\text { Longitude } \\
\text { (Degree) }\end{array}$ & $\begin{array}{l}\text { Latitude } \\
\text { (Degree) }\end{array}$ & $\begin{array}{l}\text { Ellipsoidal } \\
\text { Height } \\
\text { (Metre) }\end{array}$ & $\begin{array}{l}\text { Gravity } \\
\text { Acceleration } \\
\text { (Mgal) }\end{array}$ \\
\hline Minimum & 103.556806 & 1.365679 & 2.702093 & 978039.034000 \\
Maximum & 103.566782 & 1.637315 & 56.672284 & 978056.960000 \\
Mean & 103.561453 & 1.470588 & 20.374419 & 978050.664900 \\
Std Dev. & .004071 & 00.093475 & 23.448455 & 6.316135 \\
\hline
\end{tabular}

\section{Computation of Zero-Degree Term}

The Earth's geocentric gravitational constant $\left(G M_{E}\right)$ was derived from the EGM2008 model and the constant gravity potential of the geoid $\left(W_{0}\right)$ used in the development of EGM2008 was utilized for the study (Ince, 2011):-

$$
\begin{gathered}
G M_{E}=398600.4415 \times 10^{9} \mathrm{~m}^{3} \mathrm{~s}^{-2} \\
W_{0}=62636855.69 \mathrm{~m}^{2} \mathrm{~s}^{-2}
\end{gathered}
$$

while $G M_{0}$, the normal potential, $U_{0}$, the mean Earth radius $\mathrm{R}$ and the mean normal gravity, $\gamma$ were obtained from the reference ellipsoids as shown in Table 3 and Table 4 . The zero degree terms were computed point by point using equations (32) through (36), separately for the components that cater for the differences in the geocentric gravitational constants $\left(G M_{E}\right.$ and $\left.G M_{0}\right)$ and gravity potentials, $\left(W_{0}\right.$ and $\left.U_{0}\right)$. The mean of the zero-degree terms for the geoid undulation, gravity disturbance and gravity anomalies are shown in Table 9 through Table 11.

Table 9: Zero Order Harmonic For Geoid Undulation (Units in Metres)

\begin{tabular}{ccccc}
\hline Component & Equation & WGS84 & GRS80 & Johor2020 \\
\hline$\Delta_{G M}$ & $\frac{G M_{E}-G M_{0}}{R \gamma}$ & -0.004809 & -0.937792 & -0.937460 \\
$\nabla_{W 0}$ & $-\frac{W_{0}-U_{0}}{\gamma}$ & 0.406468 & 0.527588 & -747.286928 \\
\hline
\end{tabular}


Volume 6 Issue 24 (December 2021) PP. 226-242 DOI: 10.35631/JISTM.624022

Table 10: Zero Order Harmonic For Gravity Disturbance (Units in Mgals)

\begin{tabular}{ccccc}
\hline Component & Symbol & WGS84 & GRS80 & Johor2020 \\
\hline$\Delta_{G M}$ & $\frac{G M_{E}-G M_{0}}{R^{2}}$ & -0.000737 & -0.143803 & -0.143803 \\
$\nabla_{W 0}$ & - & 0.00 & 0.00 & 0.00 \\
\hline
\end{tabular}

Table 11: Zero Order Harmonic For Gravity Anomalies (Units in Mgals)

\begin{tabular}{ccccc}
\hline Component & Symbol & WGS84 & GRS80 & Johor2020 \\
\hline$\Delta_{G M}$ & $\frac{G M_{E}-G M_{0}}{r^{2}}$ & -0.000737 & -0.143803 & -0.143803 \\
$\nabla_{W 0}$ & $-\frac{2\left(W_{0}-U_{0}\right)}{r}$ & -0.124657 & 0.161803 & 229.261470 \\
\hline
\end{tabular}

\section{Comparison of Gravity Field Functionals}

Two sets of gravity field functionals were computed for comparison. The first set was computed from the observed ellipsoidal heights, orthometric heights and gravity accelerations of the test data, having been first converted into the respective ellipsoidal systems (i.e. WGS84, GRS80 and Johor2020) as explained above. Observed geoid undulations were computed at the 18 GNSS-levelling test points from their known ellipsoidal and orthometric heights, while the observed gravity disturbances and gravity anomalies were computed from 30 randomly selected gravity stations in the gravity accelerations data set. The second set involved the synthesis of the same points using the spherical harmonic coefficients of the EGM2008 model and the parameters of the three ellipsoids. Ignoring the topographic effects, which are functions of the orthometric height and therefore equal for all the ellipsoid systems, residual quantities were computed by subtracting the synthesized quantities from the observed ones. Table 12 through Table 20 show the statistics of the observed and synthesized geoid undulations, as well as the statistics of the residual geoid for the three ellipsoids.

Table 12: Statistics of Observed Geoid Heights (Units in Metres)

\begin{tabular}{lccc}
\hline Stats & WGS84 & GRS80 & Johor2020 \\
\hline Minimum & 7.843300 & 7.843300 & 0.948489 \\
Maximum & 8.226600 & 8.226600 & 1.357098 \\
Mean & 7.905011 & 7.905011 & 1.020311 \\
Std Dev. & 0.085289 & 0.085289 & 0.089687 \\
\hline
\end{tabular}

Table 13: Statistics of Synthesized Geoid Heights (Units in Metres)

\begin{tabular}{llll}
\hline Stats & WGS84 & GRS80 & Johor2020 \\
\hline Minimum & 7.045971 & 7.045967 & 0.167773 \\
Maximum & 7.112760 & 7.112754 & 0.226595 \\
Mean & 7.074490 & 7.074486 & 0.196538 \\
Std Dev. & 0.019507 & 0.019506 & 0.017885 \\
\hline
\end{tabular}

Table 14: Statistics of Residual Geoid (Units in Metres)

\begin{tabular}{llll}
\hline Stats & WGS84 & GRS80 & Johor2020 \\
\hline Minimum & 0.788319 & 0.788321 & 0.776199 \\
Maximum & 1.167530 & 1.167535 & 1.161025
\end{tabular}


Mean $\quad 0.830521$

0.830525

DOI: 10.35631/JISTM.624022

Std Dev.

0.086966

0.086966

0.823773

0.087095

Table 15: Statistics of Observed Gravity Anomalies (Units in Mgals)

\begin{tabular}{llll}
\hline Stats & WGS84 & GRS80 & Johor2020 \\
\hline Minimum & 17.175101 & 17.031539 & -328.670578 \\
Maximum & 30.399326 & 30.255763 & -315.369000 \\
Mean & 21.919979 & 21.776416 & -323.901523 \\
Std Dev. & 3.007764 & 3.007764 & 3.013764 \\
\hline
\end{tabular}

Table 16: Statistics of Synthesized Gravity Anomalies (Units in Mgals)

\begin{tabular}{llll}
\hline Stats & WGS84 & GRS80 & Johor2020 \\
\hline Minimum & 23.864270 & 23.720709 & -322.004025 \\
Maximum & 40.414934 & 40.271373 & -305.358945 \\
Mean & 29.316717 & 29.173157 & -316.513512 \\
Std Dev. & 5.056778 & 5.056778 & 5.082615 \\
\hline
\end{tabular}

Table 17: Statistics of Residual Gravity Anomalies (Units in Mgals)

\begin{tabular}{llll}
\hline Stats & WGS84 & GRS80 & Johor2020 \\
\hline Minimum & -15.171621 & -15.171624 & -15.164862 \\
Maximum & 1.010947 & 1.010944 & 1.022370 \\
Mean & -7.396738 & -7.396740 & -7.388011 \\
Std Dev. & 4.844157 & 4.844157 & 4.846343 \\
\hline
\end{tabular}

Table 18: Statistics of Observed Gravity Disturbances (Units in Mgals)

\begin{tabular}{llll}
\hline Stats & WGS84 & GRS80 & Johor2020 \\
\hline Minimum & 17.176146 & 17.176145 & -328.682095 \\
Maximum & 30.409652 & 30.409649 & -315.484878 \\
Mean & 21.924471 & 21.924470 & -323.952287 \\
Std Dev. & 3.009110 & 3.009110 & 2.998874 \\
\hline
\end{tabular}

Table 19: Statistics of Synthesized Gravity Disturbances (Units in Mgals)

\begin{tabular}{llll}
\hline Stats & WGS84 & GRS80 & Johor2020 \\
\hline Minimum & 25.973695 & 25.830133 & -322.132087 \\
Maximum & 42.503345 & 42.359785 & -305.329712 \\
Mean & 31.418100 & 31.274539 & -316.576947 \\
Std Dev. & 5.051157 & 5.051158 & 5.125580 \\
\hline
\end{tabular}

Table 20: Statistics of Residual Gravity Disturbances (Units in Mgals)

\begin{tabular}{llll}
\hline Stats & WGS84 & GRS80 & Johor2020 \\
\hline Minimum & -17.269859 & -17.126300 & -15.224437 \\
Maximum & -1.109711 & -0.966149 & 1.119348 \\
Mean & -9.493629 & -9.350068 & -7.375339 \\
Std Dev. & 4.838257 & 4.838258 & 4.916494 \\
\hline
\end{tabular}


Table 21: Comparison of GGMs For Synthesized Undulations (Units in Metres)

\begin{tabular}{llll}
\hline GGM & WGS84 & GRS80 & Johor2020 \\
\hline GEM10b & 7.993753 & 7.993748 & 1.115476 \\
GEM9 & 6.352223 & 6.352219 & -0.525474 \\
EIGEN-2 & 6.585380 & 6.585376 & -0.292399 \\
GGM05G & 6.787324 & 6.787320 & -0.090526 \\
EGM96 & 6.748963 & 6.748959 & -0.128874 \\
EIGEN- & 7.069696 & 7.069692 & 0.191745 \\
GRACE01s & & & \\
GGM01C & 7.114897 & 7.114893 & 0.236931 \\
OSU81 & 7.607613 & 7.607608 & 0.729472 \\
EGM2008 & 7.074490 & 7.074486 & 0.196538 \\
OSU91a & 6.762782 & 6.762778 & -0.115060 \\
\hline
\end{tabular}

\section{Conclusion}

Based on the initial studies that have been carried out, regional level ellipsoids may be used alongside global geopotential models to compute gravity field functionals, provided the respective zero-degree spherical harmonics are taken into account. Statistical comparisons of the observed gravity field functionals with those obtained by harmonic synthesis using the three ellipsoids reveal that the regional normal ellipsoid, Johor2020, performed quite well in recovering the gravity field functionals. For observed undulations, Johor 2020 obtained a mean of $1.02 \mathrm{~m}$ compared to $7.91 \mathrm{~m}$ for both WGS84 and GRS80. For synthesized undulations, an average of $0.20 \mathrm{~m}$ was obtained for Johor 2020 against $7.07 \mathrm{~m}$ for the global ellipsoids. There was little difference amongst the three ellipsoids in the values of the residual geoid and residual gravity anomalies, although Johor2020 showed some slight advantage. For the residual gravity disturbances, Johor2020 obtained a mean of $-7.38 \mathrm{mgals}$, respectively, which were smaller in magnitude than those obtained by both global ellipsoids; -9.49mgals and -9.35mgals, respectively, for WGS84 and GRS80. Comparing the synthesized undulations obtained with selected GGMs, it was found that the GGM05G provided the smallest mean of $-0.091 \mathrm{~m}$. This shows that a best-fitting regional level ellipsoid, together with a suitable geopotential model, can yield geoid undulations with zero expectation values. If the vertical datum bias is known, orthometric heights can be derived from observed ellipsoidal heights alone. In the absence of a vertical datum bias, ellipsoidal heights derived with regional level ellipsoids would equal the orthometric heights.

\section{Acknowledgement}

The authors would like to express appreciation to Universiti Teknologi Malaysia (UTM) for funding this research through the UTM Prototype Research (Vote Number; Q.J130000.2852.00L54).

\section{References}

Barthelmes, F. (2013). Definition of functionals of the geopotential and their calculation from spherical harmonic models. Deutsches Geo-ForschungsZentrum GFZ, 1, 1-5. https://doi.org/10.2312/GFZ.b103-0902-26

Bosch, W. (2000). On the computation of derivatives of legendre functions. Physics and Chemistry of the Earth, Part A: Solid Earth and Geodesy, 25(9-11), 655-659. https://doi.org/10.1016/s1464-1895(00)00101-0 


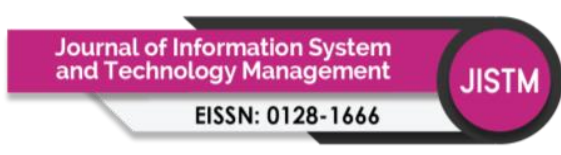

Volume 6 Issue 24 (December 2021) PP. 226-242 DOI: 10.35631/JISTM.624022

Heiskanen, W., \& Moritz, H. (1967). Physical Geodesy (J. Gilluly \& A. O. Woodford (eds.)). W H Freeman and Company.

Hirt, C. (2010). Prediction of vertical deflections from high-degree spherical harmonic synthesis and residual terrain model data. Journal of Geodesy, 84(3), 179-190. https://doi.org/10.1007/s00190-009-0354-x

Ince, E. S. (2011). Geoid Investigations for the New Vertical Datum in Canada. PhD Thesis, 20344.

Ismail, M. K., Din, A. H. M., Uti, M. N., \& Omar, A. H. (2018). Establishment of new fitted geoid model in Universiti teknologi Malaysia. International Archives of the Photogrammetry, Remote Sensing and Spatial Information Sciences - ISPRS Archives, 42(4/W9), 27-33. https://doi.org/10.5194/isprs-archives-XLII-4-W9-27-2018

Jekeli, C. (1999). An analysis of vertical deflections derived from high-degree spherical harmonic models. Journal of Geodesy, 73(1), 10-22. https://doi.org/10.1007/s001900050213

Jekeli, C. (2000). Heights, the geopotential, and vertical datums. Ohio State University, Geodetic Science and Surveying, 459, 35. http://hdl.handle.net/1811/78667

Kirby, J., \& Featherstone, W. (1997). A Study of Zero-and first-degree terms in geopotential models over Australia. Geomatics Research Australasia, 66(66), 93-108.

Kosarev, N. S., Kanushin, V. F., Kaftan, V. I., Ganagina, I. G., Goldobin, D. N., \& Efimov, G. N. (2018). Determining Deflections of the Vertical in the Western Siberia Region: The Results of Comparison. Gyroscopy and Navigation, 9(2), 124-130. https://doi.org/10.1134/S2075108718020062

Macák, M., Čunderlík, R., Mikula, K., \& Minarechová, Z. (2021). Computational optimization in solving the geodetic boundary value problems. Discrete and Continuous Dynamical Systems - Series S, 14(3), 987-999. https://doi.org/10.3934/dcdss.2020381

Meyer, T. H. (2002). Grid, ground, and globe: Distances in the GPS era. Surveying and Land Information Systems, 62(3), 179-202.

Moazezi, S., \& Zomorrodian, H. (2012). GGMCalc a software for calculation of the geoid undulation and the height anomaly using the iteration method, and classical gravity anomaly. Earth Science Informatics, 5(2), 123-136. https://doi.org/10.1007/s12145012-0102-2

Moritz, H. (1992). Geodetic reference system 1980. Bulletin Géodésique, 54(3), 395-405. https://doi.org/10.1007/BF02521480

Pavlis, N. K., Holmes, S. A., Kenyon, S. C., \& Factor, J. K. (2012). The development and evaluation of the Earth Gravitational Model 2008 (EGM2008). Journal of Geophysical Research: Solid Earth, 117(4), 1-38. https://doi.org/10.1029/2011JB008916

Petrovskaya, M. S., \& Vershkov, A. N. (2012). Basic equations for constructing geopotential models from the gravitational potential derivatives of the first and second orders in the terrestrial reference frame. Journal of Geodesy, 86(7), 521-530. https://doi.org/10.1007/s00190-011-0535-2

Sjöberg, L. E., \& Bagherbandi, M. (2017). Gravity Inversion and Integration: Theory and Applications in Geodesy and Geophysics. Springer International Publishing. https://doi.org/DOI 10.1007/978-3-319-50298-4

Torge, W. (2001). Geodesy (3rd ed.). Walter de Gruyter.

Trojanowicz, M., Owczarek-Wesołowska, M., Pospíšil, L., \& Jamroz, O. (2020). Determination of the selected gravity field functionals by the GGI method: A case study of the western Carpathians area. Applied Sciences, 10(21), 1-18. https://doi.org/10.3390/app10217892 
Volume 6 Issue 24 (December 2021) PP. 226-242 DOI: 10.35631/JISTM.624022

Tugi, A., Din, A. H. M., Omar, K. M., Mardi, A. S., Soma, Z. A. M., Omar, A. H., Yahaya, N. A. Z., \& Yazid, N. (2016). Gravity anomaly assessment using GGMs and airborne gravity data towards bathymetry estimation. International Archives of the Photogrammetry, Remote Sensing and Spatial Information Sciences - ISPRS Archives, 42(4W1), 287-297. https://doi.org/10.5194/isprs-archives-XLII-4-W1-287-2016 